\title{
Produtividade de batata-doce em função de diferentes materiais de plantio e espaçamentos entre plantas
}

\section{Sweet potato yield as a function of different planting materials and plants spacing}

\author{
Amarílis Beraldo RÓS ${ }^{1}$; Nobuyoshi NARITA²; João Carlos dos Santos NAVARRO³; \\ Maurício Dominguez NASSER ${ }^{4}$
}

\begin{abstract}
${ }^{1}$ Autor para correspondência. Pesquisadora científica, Dra em Agronomia, Agência Paulista de Tecnologia dos Agronegócios, Polo Regional Alta Sorocabana. Rodovia Raposo Tavares, km 561, Caixa Postal 298, CEP: 19015-970, Presidente Prudente, SP. amarilis.beraldo@sp.gov.br

${ }^{2}$ Pesquisador científico, Dr. em Agronomia, Agência Paulista de Tecnologia dos Agronegócios, Polo Regional Alta Sorocabana. nobuyoshi.narita@sp.gov.br.

${ }^{3}$ Técnico de Apoio a Pesquisa Científica e Tecnológica. Agência Paulista de Tecnologia dos Agronegócios, Polo Regional Alta Sorocabana.

${ }^{4}$ Pesquisador científico, Dr. em Agronomia, Agência Paulista de Tecnologia dos Agronegócios, Polo Regional Alta Paulista. mauricio.nasser@sp.gov.br.
\end{abstract}

Recebido em: 18-11-2020; Aceito em: 18-01-2021

\section{Resumo}

A implantação da cultura da batata-doce ocorre por meio do uso de segmentos do caule (ramas). Quando há pouco material vegetativo, podem-se cultivar plantas para produzir as ramas necessárias. Como essa produção representa custo, é importante verificar se as plantas oriundas de miniestacas enraizadas produzem raízes comerciais. Assim, o trabalho teve por objetivo comparar as produtividades e formatos de raízes tuberosas de plantas oriundas de miniestacas enraizadas (mudas de bandeja) e de ramas não enraizadas em função do espaçamento entre plantas na linha $(0,2 ; 0,3$ e $0,4 \mathrm{~m})$. A utilização de ramas promoveu maiores produtividades total e comercial e número de raízes que a utilização de miniestacas, independentemente do espaçamento. As plantas oriundas de miniestacas cultivadas nos espaçamentos 0,2 e 0,3 m apresentaram semelhantes produtividades total e comercial (médias de 18 e $14 \mathrm{t} \mathrm{ha}^{-1}$, respectivamente), mas valores maiores em relação ao espaçamento $0,4 \mathrm{~m}$. As produtividades total $\left(30 \mathrm{t} \mathrm{ha}^{-1}\right)$ e comercial $\left(22,5 \mathrm{ha}^{-1}\right)$ de plantas oriundas de ramas não diferiram entre os espaçamentos. O material de plantio utilizado não alterou o formato das raízes tuberosas, mas as plantas oriundas de miniestacas apresentaram raízes tuberosas com maior massa fresca. Logo, áreas cultivadas com plantas oriundas de miniestacas apresentam produções comerciais de raízes tuberosas, sendo mais indicado o espaçamento de $0,3 \mathrm{~m}$ entre plantas.

Palavras-chave adicionais: formato de raízes; Ipomoea batatas (L.) Lam.; miniestaca; multiplicação; propagação.

\begin{abstract}
Sweet potato implantation occurs using stem segments (branches). When there is little vegetative material, plants can be cultivated to produce the necessary branches. As this production represents cost, it is important to verify if the plants originating from rooted mini-cuttings can produce commercial tuberous roots. Thus, this study aimed to compare the yields and shapes of tuberous roots of plants from rooted mini-cuttings (tray seedlings) and non-rooted branches as a function of plants spacing in the line $(0.2,0.3$ and $0.4 \mathrm{~m})$. The use of branches promoted greater total and commercial yield and number of roots than the use of mini-cuttings, regardless of plants spacing. Plants from mini-cuttings cultivated in the 0.2 and $0.3 \mathrm{~m}$ spacing presented similar values of total and commercial yield (averages of 18 and $14 \mathrm{tha}^{-1}$, respectively), but higher values in relation to the $0.4 \mathrm{~m}^{2}$ spacing. The total ( $30 \mathrm{t} \mathrm{ha}^{-1}$ ) and commercial $\left(22.5 \mathrm{ha}^{-1}\right)$ yields of plants from branches did not differ between the spacing. The planting material used did not change the shape of the tuberous roots, but the plants from mini-cuttings produced tuberous roots with greater fresh mass. Therefore, areas cultivated with plants originating from mini-cuttings presents tuberous roots commercial production, being the spacing of $0.3 \mathrm{~m}$ between plants more indicated.
\end{abstract}

Additional keywords: Ipomoea batatas (L.) Lam; mini-cutting; multiplication; propagation; root shape.

\section{Introdução}

A batata-doce é originária da América Latina $e$ suas raízes tuberosas ocupam o sétimo lugar entre os alimentos vegetais mais produzidos no mundo, ficando atrás apenas do milho, arroz, trigo, batata, mandioca e tomate (FAO, 2020). É a quarta hortaliça mais consu- mida no Brasil (Peressin e Feltran, 2014), sendo a produção de 2019 correspondente a 805.412 toneladas (IBGE, 2020). No mesmo ano, o Estado de São Paulo foi o segundo maior produtor da raiz tuberosa, com 140.727 toneladas, sendo a região de Presidente Prudente, a maior produtora (IBGE, 2020). 
A implantação da cultura é frequentemente realizada por meio do uso de segmentos do caule, denominados ramas. A utilização de ramas resulta em plantas idênticas à planta-mãe, gerando lavouras com características uniformes (Brune et al., 2005).

Produtores rurais da região de Presidente Prudente têm investido no uso de ramas de batata-doce com elevada sanidade, o que tem resultado em incremento significativo de produtividade e renda. Em trabalho de Rós et al. (2012), a utilização de ramas com elevada sanidade resultou em incremento de produtividade superior a $50 \%$ em relação à utilização de ramas obtidas de lavouras comerciais. Assim, produtores têm adquirido materiais isentos de pragas e doenças para produção de plantas matrizes fornecedoras de ramas, realizando a multiplicação dessas ramas e instalando lavouras comerciais para a produção de raízes a partir dos materiais multiplicados.

No entanto, quando há poucas plantas matrizes disponíveis para o fornecimento de ramas, o material vegetativo deve ser multiplicado repetidas vezes até que se obtenha a quantidade necessária de ramas para implantação do plantio comercial. Assim, técnicas que permitam a produção de maior número de plantas a partir de limitada quantidade de ramas são necessárias. Rós \& Narita (2011) e Rós et al. (2011a) verificaram que a produção de mudas de batata-doce em bandejas a partir de segmentos com dois nós é viável.

Considerando-se que multiplicação de ramas a partir de mudas produzidas em bandeja resulta em necessidade de investimento (ambiente protegido, mão de obra, substrato, bandeja, fertilizante, irrigação, controle de pragas e doenças) é importante verificar se essas mudas produzem raízes em quantidade e qualidade suficientes para serem comercializadas e poderem custear essa etapa de multiplicação.

Raízes tuberosas de batata-doce originam-se das gemas das estacas. Dessa forma, o número de gemas enterradas influencia a produção por unidade de planta (Rós et al., 2015). De acordo com Azevedo et al. (2000), quanto menor o número de gemas enterradas por rama, há produção de menor número de raízes tuberosas de batata-doce, mas com maior massa individual. No entanto, esse resultado não foi verificado por Rós (2017), visto que o número de gemas enterradas por rama não influenciou a produtividade ou formato de raízes tuberosas.

Em trabalho de Nasser et al. (2020), a utilização de ramas com aproximadamente $0,3 \mathrm{~m}$ de comprimento resultou em produtividade total de raízes superior à verificada com o uso de miniestacas com dois ou três nós. No entanto, Islam et al. (2002) verificaram que mudas provenientes de estacas com apenas um nó apresentaram produtividade de raízes superior à de ramas com $0,3 \mathrm{~m}$ de comprimento, o que foi justificado pelo fato de as mudas já enraizadas apresentarem desenvolvimento inicial no campo mais rápido que as ramas não enraizadas. Segundo He et al. (2000), miniestacas podem apresentar maior produtividade de raízes tuberosas que ramas oriundas de lavouras comerciais, no entanto têm maior porcentagem de raízes com aspectos não comerciais.

Além do material de plantio, o espaçamento entre plantas também pode interferir na produtividade da cultura. O maior espaçamento entre plantas de batata-doce resulta em maior produção de raízes por unidade de planta (Oliveira et al., 2006, Su et al., 2011), mas não necessariamente em maior produção por unidade de área. Szarvas et al. (2019) compararam o espaçamento entre plantas de 0,2 e 0,3 m, mantendo-se o espaçamento entre leiras constante e verificaram que o menor espaçamento resulta em maior produção por unidade de área. Ogbologwung et al. (2016) também verificaram maior produtividade no espaçamento de $0,2 \mathrm{~m}$ entre plantas em relação aos espaçamentos 0,3 e $0,4 \mathrm{~m}$.

Assim, o presente trabalho teve por objetivo comparar as produtividades e formato de raízes tuberosas de plantas oriundas de estacas enraizadas com dois nós e ramas de $0,4 \mathrm{~m}$ não enraizadas em função do espaçamento entre plantas.

\section{Material e métodos}

O experimento foi realizado no município de Presidente Prudente - SP, de maio a novembro de 2019. Os dados meteorológicos ocorridos durante a condução do trabalho encontram-se na Figura 1.

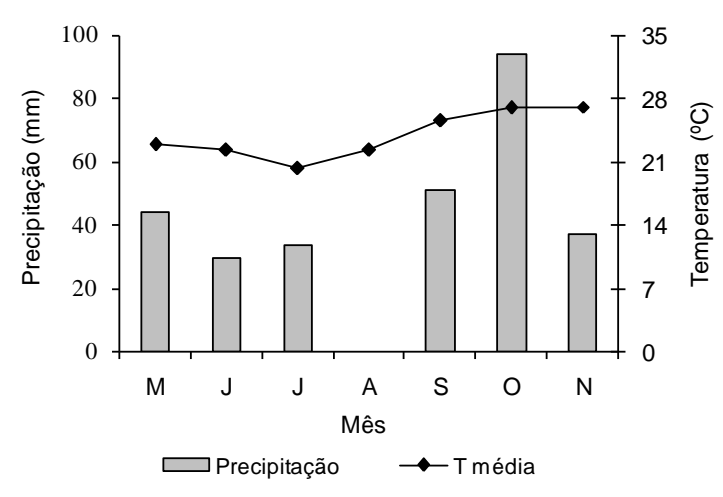

Figura 1 - Valores das precipitações pluviais mensais e das temperaturas médias mensais ocorridas de maio a novembro de 2019, na área experimental. Values of the monthly precipitation and monthly mean temperatures occurred from May to November 2019, in the experimental area. 
Em maio, foram produzidas as mudas em bandeja, em ambiente de viveiro com tela antiafídeo. Foram utilizados segmentos de ramas de batata-doce com dois nós (miniestacas), obtidos de plantas da cultivar Londrina (polpa amarelo claro e casca roxa), cultivadas em campo. Os segmentos foram retirados da porção apical das ramas (até $0,4 \mathrm{~m}$ ). Não foram utilizados os ponteiros. As folhas foram retiradas com tesoura de poda, tomando-se o cuidado de não ferir as gemas.

Os segmentos tiveram sua gema basal inserida em substrato comercial para produção de hortaliças. Foi utilizado fertilizante de liberação lenta, sendo $150 \mathrm{~g}$ de Basacote $^{\circledR}$ 16-8-12 com liberação em até três meses, seguindo recomendações de Rós et al. (2011b), e $150 \mathrm{~g}$ de Yoorin Master ${ }^{\circledR}$ por saco de substrato comercial a base de pinus $(10 \mathrm{~kg})$. Foram utilizadas bandejas com 128 células conforme indicado por Rós \& Narita (2011).

Após 35 dias do plantio das estacas, em junho de 2019, as mudas enraizadas e com folhas, foram plantadas em área de Argissolo Vermelho Amarelo preparado convencionalmente com aração, gradagem e confecção de leiras. Também foram plantadas ramas com $0,4 \mathrm{~m}$ de comprimento obtidas de ponteiros de ramas oriundas de lavoura comercial. Foi enterrada cerca de metade do comprimento das ramas, deixando-se o ponteiro exposto.

O delineamento experimental adotado foi em blocos casualizados, com seis repetições, esquema fatorial $2 \times 3$, sendo dois materiais de plantio (mudas de bandeja e ramas com $0,4 \mathrm{~m}$ de comprimento) e três espaçamentos entre plantas na linha $(0,2 ; 0,3$ e $0,4 \mathrm{~m})$. $\mathrm{O}$ espaçamento entre leiras foi de $0,9 \mathrm{~m}$. Cada parcela foi composta de três leiras de 8 metros, sendo a área útil composta pelas plantas da leira central, excluindose as duas plantas das extremidades. As populações de plantas foram de 55.555, 37.037 e 27.777 plantas por hectare para os espaçamentos entre plantas e leiras de $0,2 \times 0,9 ; 0,3 \times 0,9$ e $0,4 \times 0,9 \mathrm{~m}$, respectivamente.

A análise química do solo da área de plantio, na profundidade de $0-0,2 \mathrm{~m}$, apresentou os seguintes resultados: $\mathrm{pH}\left(\mathrm{CaCl}_{2}\right)=4,8$; matéria orgânica $=$ $=10,2 \mathrm{~g} \mathrm{dm}^{-3} ; \quad \mathrm{P}$ (resina) $=3,8 \mathrm{mg} \mathrm{dm}^{-3} ; \mathrm{K}=$ $=1,8 \mathrm{mmol}_{\mathrm{c} \mathrm{dm}}{ }^{-3} ; \mathrm{H}+\mathrm{Al}^{+3}=20,4 \mathrm{mmol}_{\mathrm{c}} \mathrm{dm}^{-3} ; \mathrm{Ca}^{+2}=$ $=10,3 \mathrm{mmol}_{\mathrm{c}} \mathrm{dm}^{-3} ; \mathrm{Mg}^{+2}=4,1 \mathrm{mmol}_{\mathrm{c}} \mathrm{dm}^{-3} ;$ CTC $=$ $=36,6 \mathrm{mg} \mathrm{dm}^{-3} ; \mathrm{e} \mathrm{V} \%=44 \%$. Foi realizada calagem na dose de $3000 \mathrm{~kg} \mathrm{ha}^{-1} \mathrm{e}$ aplicado Yoorin Master ${ }^{\circledR}$ na quantidade de $750 \mathrm{~kg} \mathrm{ha}^{-1}$, sendo incorporados até $0,3 \mathrm{~m}$ de profundidade antes do plantio. Na adubação de cobertura foi utilizado $100 \mathrm{~kg} \mathrm{ha}^{-1}$ do fertilizante 20-0-20 aos 45 dias após o plantio. A cultura recebeu irrigação por gotejamento nos períodos mais secos (junho, julho, agosto e setembro) de maneira que a as plantas recebessem cerca de $100 \mathrm{~mm}$ de água por mês (irrigação somada à precipitação), com a finalidade de manutenção do estande. Durante o período de condução a campo, foi registrado um dia de geada. Houve o controle de pragas e de plantas daninhas.

Aos 150 dias após o plantio, houve a colheita das raízes tuberosas das plantas da área útil. Foram quantificados os números total e comercial de raízes, as produtividades total e comercial, o comprimento, o diâmetro e a relação entre comprimento e diâmetro das raízes comerciais, bem como a massa fresca individual de raízes comerciais. Para produtividade e número de raízes totais, foram consideradas todas as raízes tuberosas com massa igual ou superior a $80 \mathrm{~g}$, e para a produtividade e número de raízes comerciais, as raízes tuberosas com massa fresca entre 100 e $1.000 \mathrm{~g}$, relação comprimento/diâmetro igual ou superior a 1,75 e superfície sem sulcos, rachaduras ou deformidades.

Os dados obtidos foram submetidos a análises de variância (teste F) e, quando necessário, as médias foram comparadas pelo teste de Tukey a $5 \%$ de probabilidade de erro.

\section{Resultados e discussão}

Não houve interação entre os tratamentos material de plantio e espaçamento entre plantas para as características comprimento, diâmetro, relação comprimento/diâmetro e massa fresca individual de raízes.

O comprimento das raízes tuberosas não foi influenciado pelos tratamentos, apresentando valor médio de 13,67 cm. Este valor foi próximo ao encontrado por Silva et al. (2008) quando trabalharam com 14 genótipos de batata-doce e verificaram média geral de $15,30 \mathrm{~cm}$ para o comprimento de raízes. Também não houve diferença entre ramas e mudas de bandejas para diâmetro e relação comprimento/diâmetro que apresentaram valores médios de $5,40 \mathrm{~cm}$ e 2,58, respectivamente. Em trabalho de Islam et al. (2002), plantas oriundas de miniestacas com um nó produziram raízes com maior comprimento e diâmetro que raízes provenientes de ramas com $0,3 \mathrm{~m}$, o que foi justificado pelo fato de as mudas oriundas de miniestacas terem sido mantidas em ambiente controlado favorável ao desenvolvimento de plantas com melhor qualidade.

Com relação ao espaçamento, houve diferença significativa no diâmetro, na relação comprimento/diâmetro e na massa individual de raízes (Tabela 1). O diâmetro apresentou aumento em seu valor com o aumento do espaçamento. Tal fato era esperado, pois com a maior distância entre as plantas houve menor competição por água, nutrientes e luz, o que permitiu que cada planta pudesse armazenar mais substâncias em suas raízes tuberosas. Esse maior armazenamento também pode ser observado pela superioridade da massa individual de raízes tuberosas no espaçamento entre plantas de $0,4 \mathrm{~m}$ em relação ao espaçamento de $0,2 \mathrm{~m}$. A maior massa fresca de raízes tuberosas de batata-doce também foi favorecida pelo maior espaçamento entre plantas em trabalho de Wees et al. (2016). No presente trabalho, os valores da cv. Londrina foram, em geral, superiores aos dos genótipos estudados por Guimarães et al. (2018) que, no espaçamento entre plantas de 0,3 $\mathrm{m}$, apresentaram massa média máxima de $224,7 \mathrm{~g}$. No entanto, como o 
valor do comprimento não variou em função do espaçamento entre plantas enquanto 0 diâmetro foi ampliado com o aumento do espaçamento, a relação comprimento/diâmetro apresentou diminuição de seu valor com a ampliação do espaço entre plantas, embora o valor obtido no espaçamento de $0,3 \mathrm{~m}$ não tenha diferido dos demais. Em mandioquinha salsa, o comprimento e o diâmetro não variaram em função do espaçamento entre plantas (Torales et al., 2015).

Tabela 1 - Diâmetro, relação comprimento/diâmetro e massa fresca de raízes tuberosas de batata-doce em função do espaçamento entre plantas na linha. Diameter, length/diameter and fresh mass of sweet potato tuberous roots as a function of plants spacing on the row.

\begin{tabular}{lccc}
\hline Espaçamento & Diâmetro $(\mathrm{cm})$ & Comprimento/diâmetro & Massa fresca $(\mathrm{g})$ \\
\hline $0,2 \mathrm{~m}$ & $4,80 \mathrm{~A}$ & $2,88 \mathrm{~A}$ & $201,77 \mathrm{~B}$ \\
$0,3 \mathrm{~m}$ & $5,29 \mathrm{~B}$ & $2,57 \mathrm{AB}$ & $239,53 \mathrm{AB}$ \\
$0,4 \mathrm{~m}$ & $5,81 \mathrm{C}$ & $2,30 \mathrm{~B}$ & $256,58 \mathrm{~A}$ \\
\hline $\mathrm{CV}(\%)$ & 5,38 & 10,45 & 12,78 \\
\hline
\end{tabular}

Médias seguidas de letras diferentes na coluna diferem entre si pelo Teste de Tukey $(\mathrm{p}<0,05)$. Means values followed by different letters in the columns differ significantly by the Tukey test $(p<0.05)$.

Houve diferença entre os materiais de plantio quanto à massa fresca de raízes, sendo que as mudas de bandeja promoveram raízes com maior massa individual $(253,44 \mathrm{~g})$ que a utilização de ramas $(211,81 \mathrm{~g})$. Isso se deve ao fato de que o menor número de gemas enterradas resulta na produção de menor número de raízes tuberosas de batata-doce por planta, mas com maior massa individual (Azevedo et al. 2000), devido ao armazenamento de substâncias produzidas pela planta em menor número de raízes.

Para produtividades total e comercial e números de raízes total e comercial houve interação entre material de plantio e espaçamento entre plantas.

A utilização de ramas resultou em maior produtividade total que a utilização de mudas de bandeja em todos os espaçamentos estudados (Tabela 2).

Tabela 2 - Produtividades total e comercial e números de raízes tuberosas total e comercial em função do material de plantio e do espaçamento entre plantas na linha. Total and commercial yields and total and commercial numbers of tuberous roots as a function of planting materials and plants spacing on the row.

\begin{tabular}{|c|c|c|}
\hline \multirow{2}{*}{ Espaçamento } & \multicolumn{2}{|c|}{ Material de plantio } \\
\hline & Ramas & Mudas de bandeja \\
\hline & \multicolumn{2}{|c|}{ Produtividade total de raízes tuberosas $\left(\mathrm{t} \mathrm{ha}^{-1}\right)$} \\
\hline $0,2 \mathrm{~m}$ & $27,76 \mathrm{~A} \mathrm{a}$ & $19,32 \mathrm{~A} \mathrm{~b}$ \\
\hline $0,3 \mathrm{~m}$ & $32,04 \mathrm{~A} \mathrm{a}$ & $16,72 \mathrm{~A} \mathrm{~b}$ \\
\hline $0,4 \mathrm{~m}$ & $30,22 \mathrm{~A} a$ & $11,15 \mathrm{~B} \mathrm{~b}$ \\
\hline Média & 30,01 & 15,73 \\
\hline \multicolumn{3}{|l|}{$\mathrm{CV}=14,3 \%$} \\
\hline & \multicolumn{2}{|c|}{ Produtividade comercial de raízes tuberosas $\left(\mathrm{t} \mathrm{ha}^{-1}\right)$} \\
\hline $0,2 \mathrm{~m}$ & $22,23 \mathrm{~A}$ a & $15,84 \mathrm{~A} \mathrm{~b}$ \\
\hline $0,3 \mathrm{~m}$ & $22,66 \mathrm{~A} \mathrm{a}$ & $12,67 \mathrm{~A} \mathrm{~b}$ \\
\hline $0,4 \mathrm{~m}$ & $22,76 \mathrm{~A}$ a & $7,15 \mathrm{~B} \mathrm{~b}$ \\
\hline Média & 22,55 & 11,89 \\
\hline \multicolumn{3}{|l|}{$C V=14,0 \%$} \\
\hline & \multicolumn{2}{|c|}{ Número total de raízes tuberosas (x 1000 unidades ha-1) } \\
\hline $0,2 \mathrm{~m}$ & $153,67 \mathrm{~A} \mathrm{a}$ & $77,66 \mathrm{~A} \mathrm{~b}$ \\
\hline $0,3 \mathrm{~m}$ & $142,94 \mathrm{AB}$ a & $70,03 \mathrm{~A} \mathrm{~b}$ \\
\hline $0,4 \mathrm{~m}$ & $124,24 \mathrm{~B} \mathrm{a}$ & $40,44 \mathrm{~B} \mathrm{~b}$ \\
\hline Média & 140,28 & 62,71 \\
\hline \multicolumn{3}{|l|}{$C V=13,8 \%$} \\
\hline & \multicolumn{2}{|c|}{ Número comercial de raízes tuberosas (x 1000 unidades ha-1) } \\
\hline $0,2 \mathrm{~m}$ & $125,22 \mathrm{~A} \mathrm{a}$ & $67,66 \mathrm{~A} \mathrm{~b}$ \\
\hline $0,3 \mathrm{~m}$ & $103,87 \mathrm{AB}$ a & $49,38 \mathrm{AB} b$ \\
\hline $0,4 \mathrm{~m}$ & $93,96 \mathrm{~B} \mathrm{a}$ & $26,77 \mathrm{~B} \mathrm{~b}$ \\
\hline Média & 107,71 & 47,94 \\
\hline$C V=15,8 \%$ & & \\
\hline
\end{tabular}


Não houve diferença significativa na produtividade total de raízes com a utilização de ramas, ou seja, nos três espaçamentos a produtividade média foi de $30 \mathrm{t} \mathrm{ha}^{-1}$. No entanto, a produtividade total de plantas oriundas de mudas de bandeja foi influenciada pelo espaçamento, sendo que os menores espaçamentos entre plantas $(0,2$ e $0,3 \mathrm{~m})$ resultam em semelhantes e maiores produtividades enquanto o espaçamento de $0,4 \mathrm{~m}$ resultou em menor valor. Dessa forma, pode-se inferir que no espaçamento $0,3 \mathrm{~m}$ é utilizado menor quantidade de material de propagação por área que no espaçamento de $0,2 \mathrm{~m}$, e pode favorecer melhor controle de plantas invasoras no estádio inicial da cultura quando comparado ao espaçamento de $0,4 \mathrm{~m}$ entre plantas por resultar em cobertura vegetal total da área em menor tempo.

A produtividade comercial respondeu similarmente ao apresentado pela produtividade total de raízes (Tabela 2). A produtividade de plantas oriundas de ramas foi maior que a verificada nas plantas oriundas de mudas de bandeja. Independente do material de plantio utilizado, e analisando a média dos tratamentos, nota-se que a produtividade comercial de raízes tuberosas representou aproximadamente $75 \%$ da produtividade total. Esse valor foi superior ao encontrado por Nasser et al. (2020) que trabalharam com diferentes mudas de bandeja e a produtividade comercial atingiu valor próximo de $45 \%$.

Não houve diferença entre produtividades de plantas provenientes de ramas nos espaçamentos (22,5 $\left.\mathrm{t} \mathrm{ha}^{-1}\right)$, o que está associado à diminuição na produção por unidade de planta com a redução do espaçamento entre elas, conforme verificado por Oliveira et al. (2006). A maior proximidade entre plantas pode resultar em elevada competição entre elas, promovendo inclusive a queda de produtividade. Arancibia et al. (2014) também não verificaram diferença na produtividade comercial de raízes de batatadoce em função dos espaçamentos entre plantas que, no estudo em Mississipi, foram de 0,3; 0,4 e 0,5 m. Em mandioquinha-salsa, Torales et al. (2015) relatam maior produção de raízes comerciais por unidade de área quando é utilizado maior espaçamento entre plantas.

A produtividade comercial de plantas oriundas de mudas de bandeja apresentou maiores valores nos menores espaçamentos $(0,2 \mathrm{~m}$ e $0,3 \mathrm{~m})$, ou seja, com as maiores densidades de plantio. No maior espaçamento $(0,4 \mathrm{~m})$ a produtividade comercial apresentou menor valor. A produtividade comercial média de mudas espaçadas 0,2 e $0,3 \mathrm{~m}$ foi 14,3 tha-1, semelhante a produtividade média da cultura na região de Presidente Prudente, no ano de 2019, que foi de 15,2 $\mathrm{t} \mathrm{ha}^{-1}$ (IBGE, 2020). Assim, pode-se utilizar o espaçamento de $0,3 \mathrm{~m}$ em campos de multiplicação de ramas para obter a maior produtividade de raízes utilizando-se menor quantidade de mudas por unidade de área.

Quanto aos números total e comercial de raízes, houve maiores valores nas plantas oriundas de ramas em relação às plantas oriundas de mudas de bandeja, para todos os espaçamentos, o que era esperado devido às mudas de bandeja apresentarem apenas uma gema enterrada por planta, enquanto as ramas possuem um número maior.

No número total de raízes tuberosas, os maiores valores obtidos ocorreram nos espaçamentos de 0,2 e $0,3 \mathrm{~m}$, tanto para plantas oriundas de ramas quanto para oriundas de mudas de bandejas. No entanto, para plantas oriundas de ramas, o valor verificado no espaçamento de $0,4 \mathrm{~m}$ não diferiu do quantificado no espaçamento de $0,3 \mathrm{~m}$ (Tabela 2 ).

O número de raízes comerciais, em relação ao espaçamento, apresentou comportamento semelhante entre os materiais de plantio. Os valores obtidos no espaçamento de $0,2 \mathrm{~m}$ entre plantas foram superiores aos verificados com $0,4 \mathrm{~m}$. Esse resultado era esperado visto que há maior número de gemas enterradas por metro linear no menor espaçamento entre plantas. De acordo com Wees et al. (2016) o maior espaçamento entre plantas de batata-doce resulta em maior número de raízes tuberosas por planta, mas, de acordo com os resultados do presente trabalho, esse possível incremento no número de raízes por planta não é suficiente para resultar em maior número de raízes por unidade de área. Não houve diferença nos valores obtidos no espaçamento $0,3 \mathrm{~m}$ em relação aos demais. Njoku et at. (2009) também verificaram que miniestacas com um, dois, três e quatro nós apresentaram incrementos nos números de raízes total e comercial com a diminuição do espaçamento entre plantas.

Analisando a média do número de raízes comercial e total, nota-se que aproximadamente $75 \%$ do número de raízes foram consideradas comerciais, proporção semelhante à produtividade de raízes tuberosas.

\section{Conclusão}

Áreas cultivadas com plantas oriundas de mudas de bandeja (miniestacas) apresentam produções comerciais de raízes tuberosas, sendo mais indicado o espaçamento de $0,3 \mathrm{~m}$ entre plantas.

\section{Referências}

Arancibia RA, Smith CD, LaBonte DR, Main JL, Smith TP, Vollordon AQ (2014) Optimizing sweetpotato production for fresh and processing markets through plant spacing and planting-harvest time. HortTecnology 24(1):16-24. doi: 10.21273/HORTTECH.24.1

Azevedo SM, Freitas JA, Maluf WR, Silveira MA (2000) Desempenho de clones e métodos de plantio de batata doce. Acta Scientiarum 22(4): 901-905. doi: 10.4025/actasciagron.v22i0.2839

Brune S, Silva JBC, Freitas RA (2005) Novas técnicas de multiplicação de ramas de batata-doce, Embrapa, $8 p$ (Circular Técnica 39).

FAO (2020) Faostat. Disponível em: $<$ http://www.fao.org/faostat/en/\#data/QC> (Acesso em 14 out 2020). 
Guimarães LM, Oliveira AP, Bertino AMP, Belem AB, Figueredo JP (2018) Fitomassa e produção em genótipos de batata-doce na região do brejoparaibano. Revista Agropecuária Técnica 39(1):8-14.

doi: 10.25066/agrotec.v39i1.35419

He D, Lok YH, Chun C, Kozai T (2000) Yield and growth of sweet potato using plug transplants as affected by cell volume of plug tray and type of cutting. In: Kubota C, Chun C (Ed) Transplant Production in the 21st Century, Kluwer Academic Publishers, p.154-159.

IBGE (2020) - Instituto Brasileiro de Geografia e Estatística. Sistema IBGE de recuperação automática SIDRA. Disponível em: <https://sidra.ibge.gov.br/tabela/1612\#resultado> (Acesso em 14 out 2020).

Islam AFMS, Kubota C, Takagaki M, Kozai T (2002) Sweetpotato growth and yield from plug transplants of different volumes, planted intact or without roots. Crop Science 42(3):822-826. doi: 10.2135/cropsci2002.0822

Nasser MD, Cardoso All, Rós AB, Mariano-Nasser FAC, Colombari LF, Ramos JA, Furlaneto KA (2020) Produtividade e qualidade de raízes de batata-doce propagadas por diferentes tamanhos de miniestacas. Scientia Plena 16(7):1-8.

doi: 10.14808/sci.plena.2020.070204

Njoku JC, Muoneke CO, Okocha PI, Ekeleme F (2009) Effect of propagule size and intra-row spacing on the growth and yield of sweetpotato in a humid agro-ecological zone. Nigeria Agricultural Journal 40(1):115-124. doi: 10.4314/naj.v40i1-2.55541

Ogbologwung LP, Okpara DA, Njoku JC (2016) Effect of plant spacing and variety on weed and performance of orange-fleshed sweet potato in humid agro-ecological zone of Nigeria. Uganda Journal of Agricultural Sciences 17(1):11-20. doi: 10.4314/ujas.v17i1.2

Oliveira AP, Silva JEL, Pereira WE, Barbosa LJN, Oliveira ANP (2006) Características produtivas da batata-doce em função de doses de $\mathrm{P}_{2} \mathrm{O}_{5}$, de espaçamentos e de sistemas de plantio. Ciência e Agrotecnologia 30(4):611-617.

doi: 10.1590/S1413-70542006000400003

Peressin VA, Feltran JC (2014) Batata-doce. In: Aguiar ATE, Gonçalves C, Paterniani MEGZ, Tucci MLSA, Castro CEF (ed) Instruções agrícolas para as principais culturas econômicas, 7 ed., Instituto Agronômico, p.59-61 (Boletim IAC, n. 200).
Rós AB (2017) Produtividade e formato de raízes tuberosas de batata-doce em função do número de gemas enterradas. Científica 45(3):253-256.

doi: 10.15361/1984-5529.2017v45n3p253-256

Rós AB, Araújo HS, Narita N, Tavares Filho J (2011b) Uso de fertilizante e tempo de permanência de mudas de batata-doce produzidas em bandejas. Pesquisa Agropecuária Brasileira 46(8):845-851.

doi: 10.1590/S0100-204X2011000800009

Rós $A B$, Fernandes AM, Montes SMNM, Fischer $\mathrm{IH}$, Leonel M, Franco CM (2015) Batata-doce. In: Leonel M, Fernandes Am, Franco CM (coord.) Culturas amiláceas: Batata-doce, inhame, mandioca e mandioquinha-salsa, CERAT/UNESP, p.16-120.

Rós AB, Hirata ACS, Santos, HS (2012) Avaliação da produtividade de plantas de batata-doce oriundas de matrizes livres de vírus. Revista Brasileira de Ciências Agrárias 7(3):434-439. doi: 10.5039/agraria.v7i3a1716

Rós AB, Montes SMNM, Narita N, Tavares Filho J (2011a) Technical viability of the production of sweet potato plantlets in trays. Semina: Ciências Agrárias 32(4):1423-1428.

doi: $10.5433 / 1679-0359.2011 v 32 n 4 p 1423$

Rós AB, Narita N (2011) Produção de mudas de batata-doce a partir de poucas plantas matrizes. Revista Brasileira de Ciências Agrárias 6(1):85-89. doi: 10.5039/agraria.v6i1a965

Silva CJ, Ferreira PV, Cavalcante JT, Silva JP, Santos Júnior RBS, Dourado WS (2008) Avaliação do desempenho produtivo de genótipos de batata-doce. Revista Raízes e Amidos Tropicais 4(1):37-43.

Su M, Huang J, Gan XD, Xu RL, Ye JQ (2011) Effects of plant, row spacing on growth and yield characters of sweet potato. Acta Agriculturae Jiangxi 23(5): 6-9.

Szarvas A, Hódi MS, Monostori T (2019) The effect of plant density on the yield of sweet potato. Acta Agraria Debreceniensis 1:125-128.

doi: 10.34101/actaagrar/1/2383

Torales EP, Zárate NAH, Vieira MC, Heid DM, Moreno LB, Grando VR (2015) Produtividade da mandioquinhasalsa em resposta aos espaçamentos entre plantas e peso de mudas. Bioscience Journal 31(2):433-444. doi: 10.14393/BJ-v31n2a2015-22364

Wees D, Seguin P, Boisclair J (2016) Sweet potato production in a short-season area utilizing black plastic mulch: effects of cultivar, in-row plant spacing, and harvest date on yield parameters. Canadian Journal of Plant Science 96(1):139-147. doi: 10.1139/cjps-2015-0150 